\title{
勾配ノルムに基づくヒストグラム均等化
}

\section{Gradient Norm-Based Histogram Equalization}

\author{
正会員 井上 光 平 ${ }^{\dagger}, \quad$ 原 健二十, 浦 浜 喜 ${ }^{\dagger}$
}

Kohei Inoue $^{\dagger}$, Kenji Hara ${ }^{\dagger}$ and Kiichi Urahama ${ }^{\dagger}$

\begin{abstract}
We propose a method for enhancing the contrast of grayscale images by equalizing their weighted histograms on the basis of the gradient norm, and we quantitatively evaluate the effectiveness of the proposed method.
\end{abstract}

キーワード：コントラスト強調，ヒストグラム均等化，勾配ノルム

\section{1. ま え がき}

カメラで画像を撮影する際には，コントラストの良好な 画像を取得することが望ましいが，撮影条件によっては，そ れが困難な場合もある。そこで, 画像を取得した後にコント ラストを改善するための方法が提案されている。例えば, $\gamma$ 補正やヒストグラム均等化 (histogram equalization: HE) などがよく知られているが1), 離散コサイン変換やウェー ブレット変換を用いる方法 ${ }^{2}$ なども提案されている.さら に, alpha rooting 法 ${ }^{3)}$ や HDR 画像におけるトーンマッ ピング4なども関連する技術であるといえる。Arun らは, alpha rooting 法と対数変換, べき乗則変換とを組合せた コントラスト強調法を提案している3).このように, 画像 のコントラスト改善法には様々なものがあるが, 本論文で は, 特に, HE 法の改良を目的とする. HEの拡張手法と して, 斉藤は濃度勾配ヒストグラムを用いる HE 法 (differential gray-level method: DGM) を提案し, 濃度線形変 換法, HE 法, ヒストグラム正規分布化法との比較により, DGM の有効性を示している ${ }^{5)}$. 東らは, 濃度微分特徵量ヒ ストグラムに基づく $\mathrm{HE}$ 法を提案し, 主観的評価と客観的 評価の両方で, DGM よりもよい結果を得ている6). また最 近, Ooiらは, HE 法による不自然なコントラスト強調を抑 える方法として, 平均画素值を保存するような HE 法 (bihistogram equalization with a plateau limit: BHEPL) を提案した ${ }^{7)}$. 本論文では, 画素值の変化の小さい領域にお ける過度のコントラスト強調を抑える方法として, 勾配ノル ムを重みとする HE 法 (gradient norm-based HE: GNHE)

2013 年 1 月 11 日受付, 2013 年 2 月 28 日再受付, 2013 年 3 月 13 日採録 †九州大学 大学院芸術工学研究院 コミュニケーションデザイン科学部門 (テ 815-8540 福岡市南区塩原 4-9-1, TEL 092-553-4512)

$\dagger$ Department of Communication Design Science, Faculty of Design, Kyushu University

(4-9-1, Shiobaru, Minami-ku, Fukuoka-shi, 815-8540 Japan)
を提案し, $\mathrm{BHEPL}^{7)}$ よりも高画質のコントラスト強調画像 が得られることを実験で確認する。提案手法は, DGM ${ }^{5)}$, 東らの手法 ${ }^{6)}, \mathrm{BHEPL}^{7)}$ などのように, $\mathrm{HE}$ 法の拡張手法 の一つとして位置付けることができる.

\section{2. 提 案 手 法}

$m$ 行 $n$ 列の画素の配列からなるグレースケール画像 を $f=\left[f_{i j}\right], i=1, \ldots, m ; j=1, \ldots, n$ とする. $f_{i j} \in\{0, \ldots, 255\}$ は画素 $(i, j)$ の值である.まず，画素 $(i, j)$ における画素值の垂直方向の差分を

$$
d v_{i j}= \begin{cases}d v_{i j}^{B} & \text { if }\left|d v_{i j}^{B}\right| \geqq\left|d v_{i j}^{F}\right| \\ d v_{i j}^{F} & \text { otherwise }\end{cases}
$$

で定義する。ここで

$$
\begin{aligned}
& d v_{i j}^{B}=\left\{\begin{array}{cl}
f_{i j}-f_{i-1, j} & \text { if } i-1 \geqq 1 \\
0 & \text { otherwise }
\end{array}\right. \\
& d v_{i j}^{F}=\left\{\begin{array}{cl}
f_{i+1, j}-f_{i j} & \text { if } i+1 \leqq m \\
0 & \text { otherwise }
\end{array}\right.
\end{aligned}
$$

である。同様に，水平方向の画素值の差分を

$$
d h_{i j}= \begin{cases}d h_{i j}^{B} & \text { if }\left|d h_{i j}^{B}\right| \geqq\left|d h_{i j}^{F}\right| \\ d h_{i j}^{F} & \text { otherwise }\end{cases}
$$

で定義する。ここで

$$
\begin{aligned}
& d h_{i j}^{B}=\left\{\begin{array}{cl}
f_{i j}-f_{i, j-1} & \text { if } j-1 \geqq 1 \\
0 & \text { otherwise }
\end{array}\right. \\
& d h_{i j}^{F}=\left\{\begin{array}{cl}
f_{i, j+1}-f_{i j} & \text { if } j+1 \leqq n \\
0 & \text { otherwise }
\end{array}\right.
\end{aligned}
$$

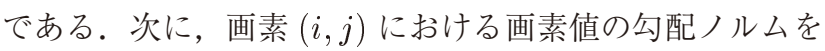

$$
w_{i j}=\sqrt{d v_{i j}^{2}+d h_{i j}^{2}}
$$

とする。このようにすると，画像の端でも勾配ノルムを計 


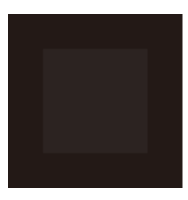

(a)

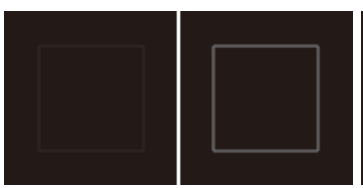

(c)

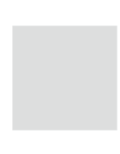

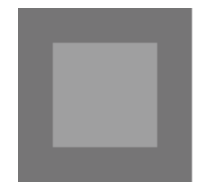

(b)
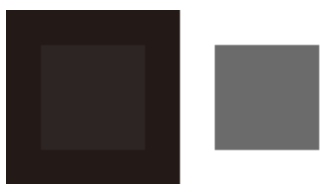

図 1 簡単な例: (a) 元画像, (b) HE の結果, (c) $w=\left[w_{i j}\right]$, (d) GNHE の結果

A simple example: (a) original image, (b) result of HE, (c) $w=\left[w_{i j}\right]$, and (d) result of GNHE.

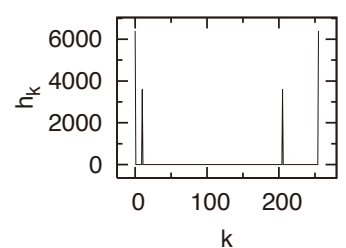

(a)

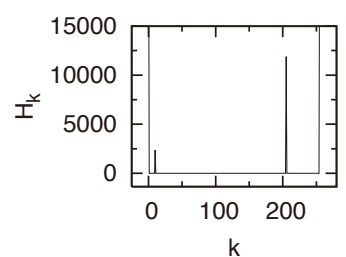

(c)

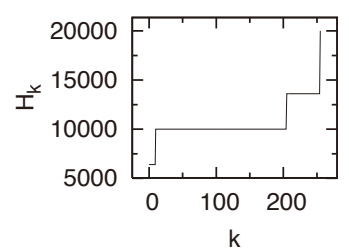

(b)

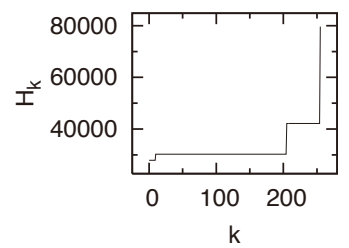

(d)
図 2 ヒストグラム $h$ とその累積 $H$ : (a) 重みなし, (b) (a) を累積したもの，(c) 重み付き，(d) (c) を累積したもの

Histograms and their cumulations: (a) unweighted, (b) the cumulation of (a), (c) weighted, and (d) the cumulation of (c).

算でき，エッジの両側で対称な勾配ノルムが得られる。本 論文では, この $w_{i j}$ をヒストグラムへの投票の重みとする重 み付き HE 法 (gradient norm-based HE: GNHE) を提案 する.すなわちヒストグラムを $h=\left[h_{k}\right], k=0, \ldots, 255$ とし，階調值 $k$ の度数を

$$
h_{k}=\sum_{i=1}^{m} \sum_{j=1}^{n} w_{i j} \delta_{k, f_{i j}}
$$

とし $\left(\delta_{k, f_{i j}}\right.$ はクロネッカーのデルタであり, $k=f_{i j}$ ならば $\delta_{k, f_{i j}}=1$ となり, その他は $\delta_{k, f_{i j}}=0$ となる), これを累積 したものを $H=\left[H_{k}\right], H_{k}=\sum_{l=0}^{k} h_{l}$ とし, コントラスト 強調画像を $g=\left[g_{i j}\right], g_{i j}=255\left(H_{f_{i j}}-H_{0}\right) /\left(H_{255}-H_{0}\right)$ とする。

\section{3. 実 験 例}

最初に，図 1 に示す簡単な例を用いて，従来の HE と GNHEの違いを説明する。図 1(a) の画像は, 左右が黒 $\left(f_{i j}=0\right)$ と白 $\left(f_{i j}=255\right)$ の領域に分かれており，黒
領域の中心には $f_{i j}=10$ の矩形領域 $R_{L}$ があり, 白領域の 中心には $f_{i j}=205$ の矩形領域 $R_{R}$ がある. $R_{L}$ は, 周囲 の黒領域との画素值の差が小さいため視認しにくい.この 画像に HE を施すと, 図 $1(\mathrm{~b})$ に示すように $R_{L}$ が明瞭にな る.ここでは Paint Shop Pro (Ver. 7.04) のヒストグラム 機能 (平均化) を用いた。このように HEでは, 視認できな いほどの画素值の差も強調されることがあり，これが擬似 輪郭を生じたり, 平均画素值を大きく変化させるような不 自然なコントラスト強調を引き起こす原因になる。このよ うな好ましくない強調を抑えるために, GNHEでは画素值 の勾配ノルムを利用する。図 $1(\mathrm{c})$ に勾配ノルム $w=\left[w_{i j}\right]$ を画像化したものを示す。この画像では, 中央の白と黒の 境界における勾配ノルムが最も大きく, その次に右側の $R_{R}$ の境界における勾配ノルムが大きい. 左側の $R_{L}$ の境界に おける勾配ノルムは $R_{R}$ のそれに比べて小さい.この $w$ を 重みとして HE を行った結果を図 1(d) に示す。眓 1(b) と 比較すると, 黒領域と $R_{L}$ の間の過度のコントラスト強調 が抑えられている。このような結果になる理由を，図 2 に 示すグラフを用いて説明する。図 2(a) は, 図 1(a) の画像 の重みなしヒストグラム (すなわち, (8) 式で $w_{i j}=1$ と したもの) を表しており，縦軸は $h_{k}$ であり，横軸は $k$ であ る。このグラフには四つのピークがあり，それらは左から 順に, 黒領域, 矩形領域 $R_{L}$, 矩形領域 $R_{R}$, 白領域に対応 している。このグラフを累積すると, 図 2(b)のような階段 状のグラフが得られる。この階段状のグラフの段差の大き さは, コントラスト強調の度合いを表しており, 例えば, 左 端の短い水平線分は，黒領域と $R_{L}$ の間のコントラストが 低いことを表しており，それに続く垂直の線分は，これら 2 領域間のコントラストが垂直線分の長さに応じた度合い で強調されることを表している。この段差の大きさは， $R_{L}$ の面積が広いほど大きくなり，黒領域と $R_{L}$ のコントラス トの高低とは無関係である. 図 $1(\mathrm{a})$ の画像の場合, $R_{L}$ の 面積がある程度広いため, それに応じて図 1(b)では, 黒領 域と $R_{L}$ のコントラストが強調されている. 一方, 図 2(c) に示す重み付きヒストグラムでは，(7) 式の勾配ノルムを 重みとするため, 黒領域と $R_{L}$ の境界における勾配ノルム が小さいことから, 左から 2 番目のピークが相対的に小さ くなり, その結果, 図 $2(\mathrm{~d})$ に示すように, 左端の段差は小 さくなり, 黒領域と $R_{L}$ の間のコントラスト強調は抑えら れる。

次に，実際のグレースケール画像のコントラスト強調の 結果を図 3 に示す。眓 3(a) は元の画像であり, 図 3(b), (c) はそれぞれ HE, GNHE の結果である。図 3(b) ではカメ ラマンの顔に擬似輪郭が生じたり, 空の領域における横線 状のノイズが強調されたりしているが, 図 3(c) ではそのよ うな不自然なコントラスト強調が抑えられている。図 4 に 元画像 (図 3(a)) の $h$ と $H$ を示す. 図 4(a), (b) はそれぞ れ重みなしの $h, H$ であり, 図 $4(\mathrm{c}),(\mathrm{d})$ はそれぞれ重み 付きの $h, H$ である. 図 4(d) は図 $4(\mathrm{c})$ よりも滑らかであ 


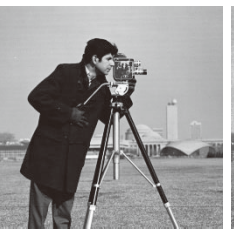

(a)

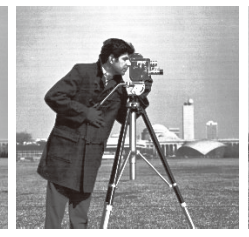

(b)

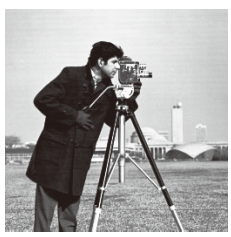

(c)
図 3 グレースケール画像のコントラスト強調: (a) 元画像, (b) HE の結果, (c) GNHE の結果

Contrast enhancement of a grayscale image: (a) original image, (b) the result of HE, and (c) the result of GNHE.

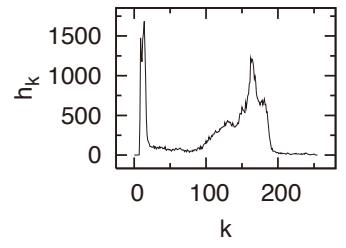

(a)

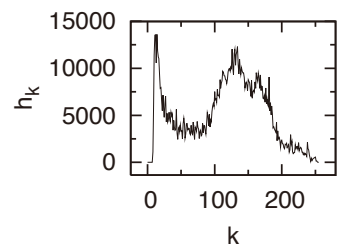

(c)

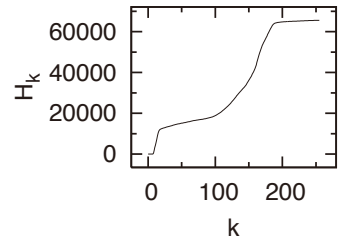

(b)

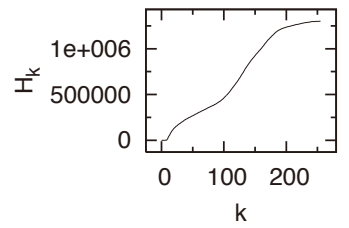

(d)
図 4 元画像 (図 3(a)) のヒストグラム $h$ とその累積 $H:$ : (a) 重みなし，(b)（a）を累積したもの，(c) 重み付き，(d) (c)を累積したもの

Histograms and their cumulations of Fig. 3(a): (a) unweighted, (b) the cumulation of (a), (c) weighted, and (d) the cumulation of (c).

り, GNHE では不自然なコントラスト強調が抑えられるこ とを示している。また, GNHEによるコントラスト強調画 像 (図 3(c)) の $h$ と $H$ を図 5 に示す。図 5(a), (b) はそれ ぞれ重みなしの $h, H$ であり, 図 $5(\mathrm{c}),(\mathrm{d})$ はそれぞれ重み 付きの $h, H$ である. 図 $5(\mathrm{~d})$ は図 $5(\mathrm{c})$ よりも直線的であ り, GNHEによって重み付きヒストグラムが均等化されて いることを示している.

他の画像での結果を図 6 に示す。上段は元画像であり, 中段は $\mathrm{BHEPL}^{7)}$ の結果であり，下段は GNHEの結果であ る.両手法で不自然さの少ないコントラスト強調ができて いる. Jobson らの画質評価指標 ${ }^{8)}$ による定量的評価の結果 を図 7 に示す。横軸のアルファベットは図 6 の列に付けた ものに対応し, 縦軸は評価值を表す。この值が大きいほど画 質がよいとされる，GNHEによる值が $\mathrm{BHEPL}^{7}$ による值 を上回っており, 提案手法による画質の改善が確認された.

図 6(d)-(f) の部分拡大画像を図 8(a)-(c) に示す。図 8 の 上から 1 段目は入力画像である. 2 段目は HE 法の結果であ り, 図 6 には示していないが, 比較のために追加している. 3,4 段目はそれぞれ $\mathrm{BHEPL}^{7)}$ と GNHEの結果である。ま ず，図 8(a)では，HE法 (2 段) によってノイズが強調され ているが, $\mathrm{BHEPL}^{7)}(3$ 段) では HE 法 (2 段) ほどノイズ

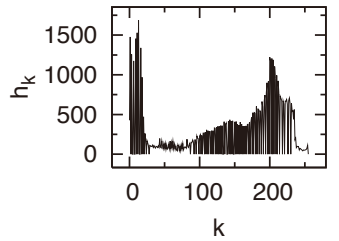

(a)

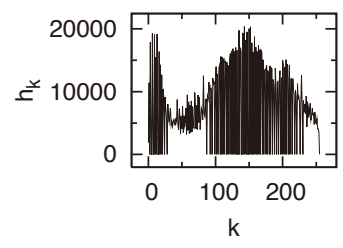

(c)

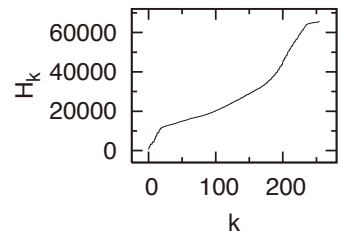

(b)

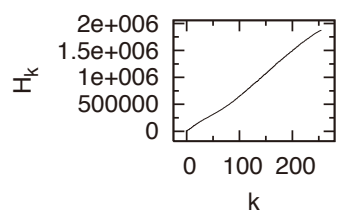

(d)
図 5 GNHE によるコントラスト強調画像 (図 3(c)) のヒスト グラム $h$ とその累積 $H$ : (a) 重みなし, (b) (a) を累積 したもの, (c) 重み付き, (d) (c) を累積したもの

Histograms and their cumulations of Fig. 3(c): (a) unweighted, (b) the cumulation of (a), (c) weighted, and (d) the cumulation of (c).

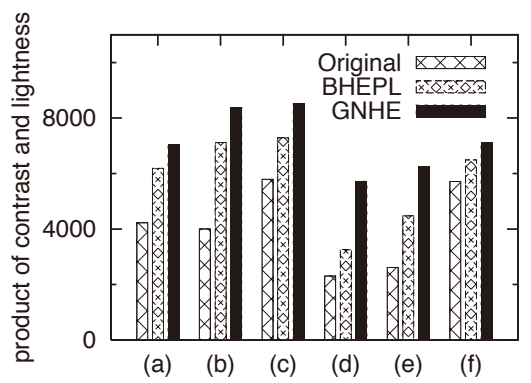

図 7 Jobson の方法 ${ }^{8)}$ による図 6 の画像の定量的評価 Quantitative evaluation of the images in Fig. 6 by Jobson's method ${ }^{8)}$.

は強調されていない. $\operatorname{GNHE}(4$ 段 $)$ では, $\mathrm{BHEPL}^{7)}(3$ 段 $)$ よりもノイズの強調が目立つが HE 法 (2 段) ほど強くはな く, 壁の明暗の差は $\mathrm{BHEPL}^{7)}(3$ 段 $)$ よりも明瞭になってい る。図 8(b)では, $\mathrm{BHEPL}^{7)}(3$ 段 $)$ がノイズの強調を抑え たコントラスト強調ができており, GNHE(4 段) は HE 法 (2 段) と同程度にノイズを強調している。図 8(c) では, HE 法 (2 段)によるノイズの強調が目立ち, $\mathrm{BHEPL}^{7)}(3$ 段 $)$ が 最もノイズの強調が抑えられており， $\operatorname{GNHE}(4$ 段 $)$ はそれ

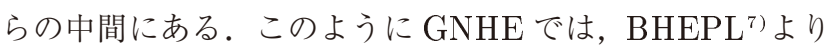
も平坦な部分におけるノイズを強調する傾向がある。これ は, 個々のノイズが小さくても平坦な部分が広いと, 平坦 な部分の階調值のヒストグラムの度数が大きくなるためで あると考えられる。 また，図 6(d) の (下段) では, 手前の 白い部分が白飛びしていることから，元画像のエッジ部が 特定の明度域に集中していると, それ以外の明度域でのコ ントラストが結果的に潰れてしまうこともあると考えられ る。これらのことから, GNHEは，平坦な部分にノイズが ほとんどない画像, 平坦な部分の面積が狭い画像, エッジ 部が広い明度域に分布する画像のコントラスト強調に適し ていると考えられる。 


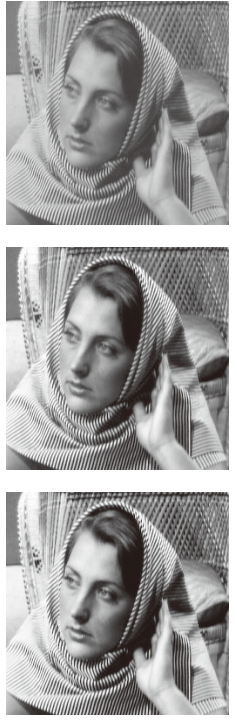

(a)
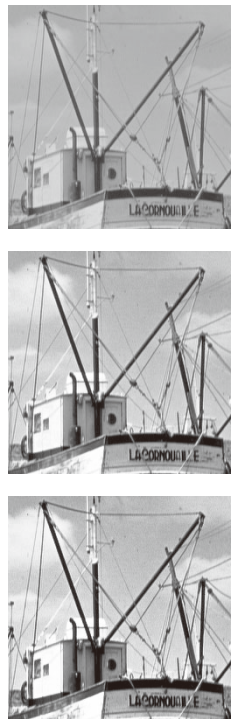

(b)
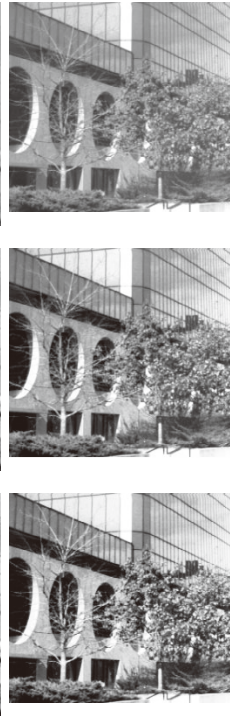

(c)
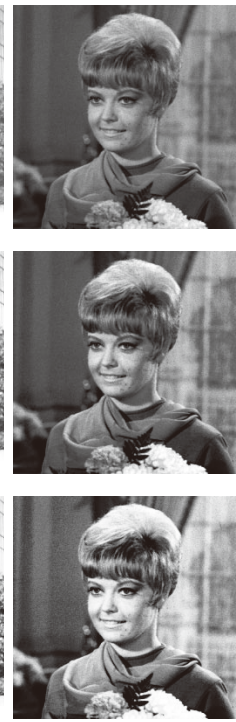

(d)
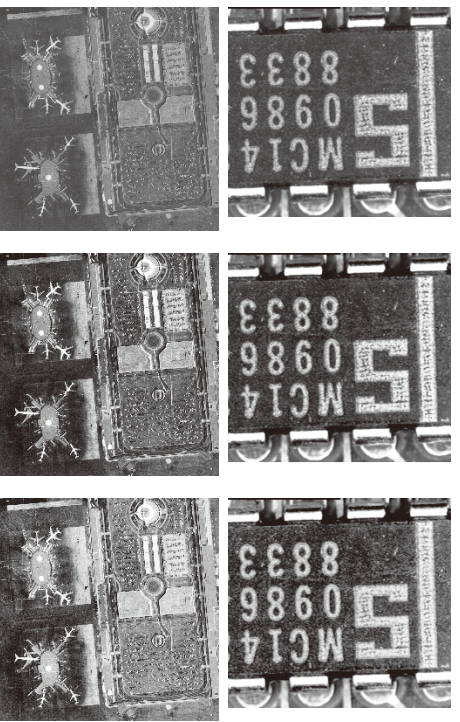

(e)

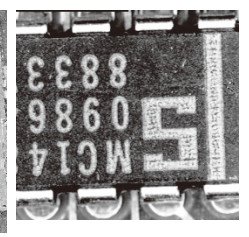

(f)

図 6 他の結果: (上段) 元画像, (中段) BHEPL ${ }^{7}$ ) の結果, (下段) GNHE の結果 Other results: (top) original images, (middle) the results of BHEPL ${ }^{7}$, and (bottom) the results of GNHE.
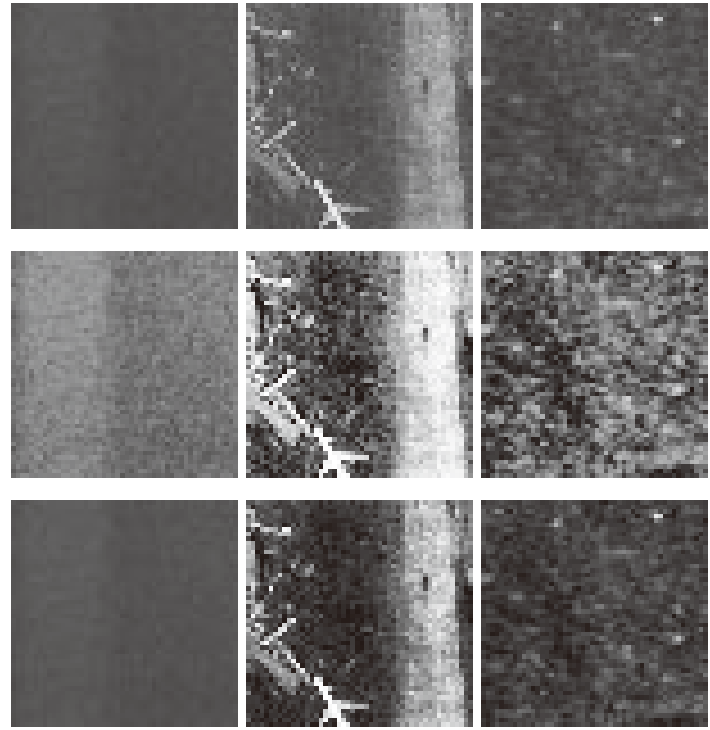

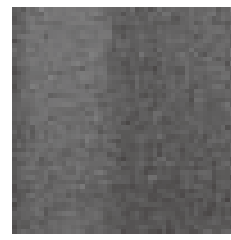

(a)

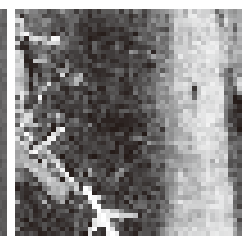

(b)

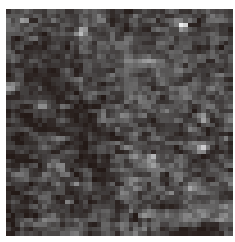

(c)
図 8 部分拡大画像: (1 段) 元画像, (2 段) HE 法の結果, (3 段) BHEPL $^{7)}$ の結果, (4 段) GNHE の結果; (a) 図 6(d) の 左奥の壁, (b) 図 6(e) の下部の中央付近, (c) 図 6(f) の 右上の暗部

Zoomed parts: (1st row) original images, (2nd row) the results of $\mathrm{HE}$, (3rd row) the results of $\mathrm{BHEPL}^{7}$ ), and (4th row) the results of GNHE; (a) the left back wall in Fig. 6(d), (b) the lower part around the center of Fig. 6(e), and (c) the upper-right dark part in Fig. 6(f).

\section{4. むす び}

勾配ノルムを重みとするヒストグラム均等化を提案し， 従来手法よりも高画質のコントラスト強調画像が得られる
ことを実験で確認した。カラー画像への拡張が今後の課題 である。

\section{〔文献〕}

1) R. C. Gonzales and R. E. Woods: Digital Image Processing (3rd Edition), Prentice Hall (2007)

2) R. Chouhan, C. P. Kumar, R. Kumar, and R. K. Jha: "Con" trast Enhancement of Dark Images using Stochastic Resonance in Wavelet Domain", IJMLC, 2, 5, pp. 711-715 (2012)

3) Arun R, M. S. Nair, R. Vrinthavani, and R. Tatavarti: "An alpha rooting based hybrid technique for image enhancement", Engineering Letters, 19, 3, pp. 159-168 (2011)

4) G. Qiu, J. Guan, J. Duan, and M. Chen: "Tone Mapping for HDR Image using Optimization - A New Closed Form Solution", Proc. ICPR, pp. 996-999 (2006)

5）斉藤文彦: “濃度勾配ヒストグラムによる画像のコントラスト改善”, 電 気学論. C, 126, 2, pp. 228-236 (2006)

6）東佑馬, 斉藤文彦: “濃度微分特徵量ヒストグラムに基づく画像のコント ラスト改善”，電気学論. C, 127, 5, pp. 705-711 (2008)

7) C. H. Ooi, N. S. P. Kong, and H. Ibrahim: "Bi-histogram equalization with a plateau limit for digital image enhancement", IEEE Trans. Consumer Electronics, 55, 4, pp. 2072-2080 (2009)

8) D. J. Jobson, Z. Rahman, and G. A. Woodell: "The statistics of visual representation", in Visual Information Processing (2002)

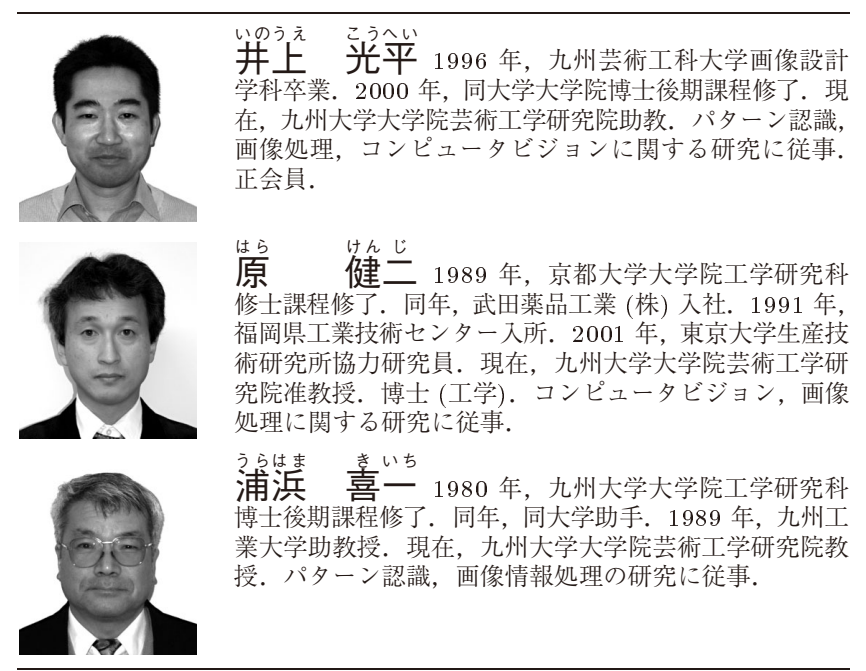

